\title{
Mulheres feministas e evangélicas: a construção racional de uma nova identidade a partir dos estudos de gênero e do acesso ao ensino superior
}

Milena Geisa Dos Santos Martins ${ }^{1}$

\begin{abstract}
Resumo: No presente artigo, busco mostrar a integração da inteligibilidade de racionalidades aparentemente inconciliáveis de mulheres que, ao unirem feminismo e religião, construíram, para si e perante os outros, novas identidades. Destaco ainda que os tensionamentos advindos do ativismo das evangélicas feministas refletem, de modo mais amplo, um campo de análises que complexifica os estereótipos do senso comum, que concebe as mulheres religiosas - particularmente as evangélicas - como submissas e dóceis. Objetivo interpretar o universo dessas mulheres a partir de entrevistas e de netnografias feitas em ambientes virtuais, utilizados por elas, na rede social Facebook, e elaborar um material que contribua para o fomento de novas racionalidades - tanto na academia quanto na sociedade - mediante o suporte de análises teóricas dos estudos de gênero e da religião.
\end{abstract}

Palavras-chave: Gênero. Religião. Violência de gênero. Evangélicas progressistas.

\section{Women Feminists and evangelicals: the rational construction of a new identity based on gender studies and in the access of Higher Education}

\begin{abstract}
In this article, i mean to show an integration between intelligibility of apparently irreconcilable rationalities of women who, by uniting feminism and religion, have builded, for themselves and exhibited others, new identities. I also point out that the came from tensions of the activism of evangelical women reflect, more broadly, a field of analysis that complexes the stereotypes of common sense that conceive a religious woman, especially evangelical women, as submissive and docile. I objective to interpret the universe of these women, through interviews and netnography of virtual spaces on social Facebook, and to elaborate a material that contributes to foster new rationalities, both in academia and in society, using the support of theoretical analyzes of gender studies and religion.
\end{abstract}

Keywords: Gender. Religion. Gender violence. Progressive evangelicals.

Mestra em Ciências Sociais, com experiência em Pesquisa sobre Gênero, Religião e Ativismo Digital. Pesquisadora do CRELIG (Grupo de Pesquisa Dinâmicas Territoriais, Cultura e Religião). E-mail: milenamartins18@gmail.com 


\section{Introdução ${ }^{2}$}

Becker (2008) afirma que, ao fazermos uma pesquisa, não devemos ir a campo esperando saber todas as respostas. Em concordância com Becker, afirmo que, desde o princípio, estou na contramão do que pensa o senso comum a respeito das mulheres evangélicas. Embora pareçam ser mulheres submissas, acríticas e extremamente dedicadas à família, em minha concepção, faz-se necessário praticar o que Da Matta (1978) chama de Anthropological Blues e, desse modo, estranhar o que é familiar e familiarizar-se com o que é exótico. Nesse sentido, acredito que foi enriquecedor voltar meu olhar para as evangélicas feministas, objetivando descobrir o que há por trás do estereótipo, e até mesmo do preconceito, em relação a elas. Meu primeiro contato com as Feministas Evangélicas ${ }^{3}$ deu-se por meio do grupo virtual na rede Facebook, chamado "Feministas Cristãs" . No grupo, só é permitido o acesso de mulheres após análise e aprovação das mediadoras. Sendo assim, afirmo que minha inserção no grupo ocorreu sem maiores esforços.

Embora a categoria "evangélica” possua ampla segmentação, não é objetivo aqui tratar a particularidade de cada vertente denominacional. Para isso, há outros autores que cumpriram plausivelmente com a proposta de identificar e discernir as particularidades de cada grupo desde sua fundação, como, por exemplo: Clara Mafra ${ }^{5}$ e Antonio Gouvêa Mendonça ${ }^{6}$. Admoesto, portanto, que, apenas para a análise, concebi o cristianismo como um bloco religioso monolítico pelo fato de este ter sido construído mediante bases patriarcais. Portanto, defendo que tratar a relação de gênero dentro do meio evangélico, de modo mais abrangente - e não aprofundado nas peculiaridades dogmáticas de cada denominação - é fundamental, pois a estrutura que compõe os segmentos religiosos tidos como evangélicos é a mesma. Dito de outro modo, em lugar de aprofundar-me nas particularidades de cada denominação, optei por identificar e estudar as questões que perpassavam "todas" elas. E, como já era esperado, constatei que a violência de gênero é a base de todas as outras.

2 No final da graduação, tomei conhecimento sobre a existência de um grupo virtual formado - somente - por mulheres feministas e evangélicas, no Facebook. Sem dúvida, a oportunidade de entender a respeito desse universo, aparentemente antagônico, instigou-me e moveu-me, não só como pesquisadora, mas também por ser uma mulher nascida e criada em família cristã. Portanto, decidi estudar o feminismo evangélico na Pós-Graduação, de modo que o presente artigo, no qual discuto mudanças no que tange à transformação de identidades de mulheres evangélicas ao se descobrirem feministas, é um recorte de minha dissertação de Mestrado.

3 Destaco aqui que as Feministas Evangélicas são mulheres que se autodenominam evangélicas e também feministas.

4 Nome dado a um grupo privado na rede social Facebook, do qual participam mulheres católicas, kardecistas e também evangélicas. A escolha do nome - Feministas Cristãs - deu-se pelo fato de as idealizadoras do grupo terem a intenção de agregar demais religiões cristãs que não somente a evangélica em virtude de reconhecerem muitas similitudes em relação a essas correntes religiosas. Para além das aproximações e similitudes religiosas, o próprio gênero é fato de aproximação entre as integrantes. Segundo uma das idealizadoras, o que uma mulher católica sofre não diferente tanto das experiências vivenciadas por kardecistas ou evangélicas, tanto nos ambientes religiosos, quanto no doméstico, exclusivamente pelo fato de serem mulheres.

5 MAFRA, Clara. Os evangélicos. Rio de Janeiro: Jorge Zahar, 2001.

6 MENDONÇA, Antonio Gouvêa. Protestantismo no Brasil: um caso de religião e cultura. Revista USP, São Paulo, n. 74, p. 160-173, jul/ago 2007. MENDONÇA, Antonio Gouvêa. O protestantismo no Brasil e suas encruzilhadas. Revista USP, São Paulo, n. 67, p. 48-67, set/nov. 2005. 
No tocante à metodologia, realizei este estudo por meio de informações coletadas por etnografia multissituada ${ }^{7}$ e de entrevistas virtuais. Toda pesquisa de campo pode ser multissituada, pois informações relevantes podem ser apreendidas por meio da observação de outros lugares para além daquele que o objeto de estudo ocupa (MARCUS, 2001). Optei por essa forma de acompanhamento ao perceber que as feministas evangélicas atuam de modo descentralizado no ambiente virtual, passando a ter visibilidade em outros veículos de informações virtuais ${ }^{8}$ e/ou de mídia tradicional ${ }^{9}$. Portanto, a etnografia multissituada me instrumentalizou na busca por pontos de congruência em meio a diferentes interconexões de pensamentos, vivências, práticas e discursos desenvolvidos e manifestados em mais de um ambiente ${ }^{10}$. Tenho consciência de que, ao voltar meu olhar para múltiplos campos de análises, corro o risco de não coletar dados importantes. Porém não objetivo fazer análises completas de todo o conteúdo disponibilizado por elas, em cada sítio virtual, mas sim, realizar a integração entre dados e fatos recorrentes.

Embora tendo em mente que "a observação direta e participativa dentro da comunidade permite ao etnógrafo desenvolver uma percepção acurada e extremamente sensível às variações comportamentais nas relações entre os membros das comunidades digitais" (LEMOS; LEVY, 2010, p. 227), decidi realizar - para além da etnografia multissituada - entrevistas em profundidade. Isso porque, em concordância com Duarte (2002), acredito que: "alguém do meio, a partir do próprio ponto de vista, tem, relativamente, melhores condições de fornecer informações sobre esse meio do que alguém que observa, inicialmente fora" (DUARTE, 2002, p. 143). Então, realizei entrevistas semiestruturadas ${ }^{11}$ e em profundidade, pois entendi o discurso proferido pelas informantes como sendo uma versão real e, portanto, representativa de suas vivências. Desse modo, a partir das narrativas das entrevistas, foi possível identificar repetições que levaram a um ponto de "saturação", permitindo retornar à teoria e começar a produzir o material final da pesquisa, tal qual recomenda Duarte (2002).

Ao todo foram entrevistadas 8 (oito) mulheres, negras e brancas, dentro de uma faixa etária que variou entre 20 e 40 anos de idade. É importante destacar que todas possuem ensino superior completo e têm posição socioeconômica semelhante. Entretanto, não será possível mencionar posicionamento de todas neste artigo, devido ao formato sucinto de texto. Também se faz necessário ressaltar que, vislumbrando proteger a identidade das entrevistadas, os nomes mencionados neste estudo são fictícios. Iniciei as entrevistas com as moderadoras do grupo Feministas Cristãs e com idealizadoras das páginas Evangélicas pela Igualdade de Gênero ${ }^{12}$.

Esta técnica também é utilizada em pesquisas sobre mídias, ciência e tecnologia, estudos feministas... A técnica foi utilizada para analisar o grupo e as páginas nas quais as feministas evangélicas se manifestam, para ler matérias que saíram a respeito delas na rede.

8 As Feministas Evangélicas do grupo Feministas Cristãs, por exemplo, foram entrevistadas pela BBC.

9 A fundadora da página Frente Evangélica pela Legalização do Aborto teve uma participação no programa Amor e Sexo da Rede Globo, no ano de 2018. Disponível em: https://globoplay.globo.com/v/7159808/. Acesso em: 13 de novembro, 2018.

10 Tais como: o grupo Feministas Cristãs e as páginas Evangélicas pela Igualdade de Gênero, Frente Evangélica pela Legalização do Aborto e Projeto Redomas - todos na rede social Facebook.

11 Entretanto, as entrevistadas estavam livres para fazerem toda e qualquer colocação.

12 Embora estivesse no planejamento entrevistar também a idealizadora da página Frente Evangélica pela Legalização do Aborto, não obtive seu retorno após algumas tentativas de contato. 


\section{Feminismo e religião: um encontro transformador de identidades femininas}

Rosado-Nunes (2001), partindo de um debate teórico central, lança-nos a pergunta: “Será mesmo possível um encontro entre o feminismo e a religião?" Embora, segundo a autora, não seja usual que os estudos da religião contemplem a temática de gênero e os estudos de gênero não possuam seu foco na religião, eles são contemporâneos um ao outro. Ambos surgiram no meio acadêmico, durante as décadas de 1950 e 1960 do século XX, e é na teologia feminista ${ }^{13}$ que podemos encontrar esses dois campos do saber de modo articulado, mesmo que ainda de modo incipiente. Segundo a autora, os estudos de religião e gênero se estabeleceram no meio acadêmico devido ao capital simbólico e material das religiões, advindos principalmente do catolicismo e de agências internacionais de apoio à pesquisa.

Embora ainda hoje a "aparição" de mulheres que se professem feministas e evangélicas cause estranhamento no cenário público, identifiquei, no trabalho da autora supracitada, que a união desses campos aparentemente antagônicos já ocorre há mais de 50 anos. Por isso, academia é importante como um vetor promotor de novas inteligibilidades mediante a aquisição de novos conhecimentos. Entre as Feministas Evangélicas, percebemos que a presença da educação de ensino superior é expressiva. Além de todas as entrevistadas neste estudo serem graduadas e pós-graduadas, uma das moderadoras da página Evangélicas pela Igualdade de Gênero - na rede social Facebook - afirmou que 70\% das seguidoras são graduadas em Teologia ou em Ciências Sociais.

É interessante recomendar, para pesquisas futuras, que, embora meu objeto advenha de vertentes evangélicas pentecostais e neopentecostais, reconhecidas nos estudos da Sociologia da Religião por serem formadas por indivíduos provenientes de camadas baixas, parece que a presença dessas mulheres religiosas nos espaços acadêmicos pode ter sido favorecida pelos programas de inclusão social desenvolvidos e implementados durante os governos de Luiz Inácio Lula da Silva e Dilma Rousseff, que objetivavam tornar viável o direito da população carente de ter acesso à educação superior pública e de qualidade.

Destaco ainda que, por meio de informações professadas pelas entrevistadas, o ensino superior é um maximizador de conhecimentos e desconstrutor de fundamentalismos alicerçados pela religião. A respeito dessa afirmação, trago o relato de Ester:

Eu vim de uma família muito pobre e fui a primeira da minha família me formar numa universidade federal, e a maioria nem tem ensino médio. Eu sempre quis estudar porque eu sempre vi a educação como forma de abrir portas. E ao longo dos anos eu fui estudando sobre o feminismo, pesquisando e a Universidade me ajudou muito. Então eu fui me vendo como uma mulher feminista. Viver pra Cristo é, às vezes, negar a si mesmo. Mas o feminismo, a instrução, a universidade me ajudaram a perceber algumas coisas dentro da religião. Algumas coisas que não são de Cristo. Então, essas coisas fizeram com que eu me afastasse da religiosidade. A Rural é uma Universidade muito boa porque você conhece todo tipo de gente. Eu me vi na Rural, uma assembleiana tradicional, e ali eu aprendi muitas coisas com as pessoas, conheci muitos outros cristãos que são cristãos. Aquela vivência me fez muito bem porque mudou o meu olhar em relação ao cristianismo". (Ester)

13 Segundo Rosado-Nunes (2001), a maior produção feminista teológica no Brasil vem das vertentes protestante e católica, que possuem institucionalização e respeito da academia. 
Portanto, a partir dos conhecimentos adquiridos no ensino superior ${ }^{14}$, novas visões e interpretações de mundo se construíram. Por isso, percebi que, para as Feministas Evangélicas, houve o rompimento com a percepção que elas tinham a respeito da religião. Consequentemente, essas mudanças na forma de pensar culminaram com mudanças no modo de agir. Também Guedes (2009) aponta que a aquisição de educação formal traz novas visões de mundo para as mulheres e amplia o universo de escolhas femininas.

Para Butler (2015), reconhecer-se em uma nova identidade faz com que as referências de passado não façam sentido no presente e por isso o sujeito não volta a ser o que fora anteriormente. Percebo que, a partir de conhecimentos teóricos e novas vivências em ambiente institucional acadêmico, mulheres adquiriram repertório crítico que as possibilitou deixarem de seguir um sistema religioso de regras baseadas na submissão e na obediência feminina. Ou seja, para as Feministas Evangélicas, a aquisição do ensino superior foi o principal fator para a desconstrução da concepção dos tradicionais papéis de gênero implantados pela religião.

No meio evangélico, para além das mensagens propagadas pelas lideranças religiosas durante os cultos nas igrejas, lideranças tecem, como estratégias de dominação de gênero disfarçada de ações orientadas à formação e defesa da família - eventos externos, com foco no público feminino. O Congresso de Mulheres Diante do Trono, o Culto das Princesas e o projeto Godllywood ${ }^{15}$ têm por objetivo doutriná-las para submissão ao marido e para o desempenho dos trabalhos não remunerados de reprodução social e care. No Congresso Mulheres Diante do Trono ${ }^{16}$, ministrado por Ana Paula Valadão ${ }^{17}$, por exemplo, as orientações transmitidas às fiéis abordam o cuidado com a apresentação pessoal e a conduta feminina. É pregado que a mulher deve cuidar do corpo e da aparência, além de se relegar ao seu lugar de esposa e mãe, pois este foi, segundo creem os evangélicos, o papel destinado a elas por Deus, dentro família. Além disso, a cantora e pastora defende que, se alguém nasce mulher, é porque Deus quis. Logo, dentro da lógica religiosa, desempenhar os tradicionais papéis de gênero ao cuidar da família e do marido é o mesmo que obedecer a Deus. Valadão declara, ainda, em suas pregações, que é contra as conquistas adquiridas pelas mulheres, por meio das lutas feministas, defende que tais conquistas afastam as mulheres de Deus e que a verdadeira felicidade para as mulheres só pode ser atingida através da obediência à vontade divina (ROSAS, 2016).

14 Mendonça (2005) faz um mergulho no passado e nos mostra que a aquisição do ensino superior por indivíduos religiosos foi um vetor de extrema importância para a transformação de seus valores e visão de mundo. Segundo o autor: “O protestantismo, já em sua terceira geração no Brasil, formara em seu seio uma juventude burguesa intelectualizada pelo acesso às universidades que foram surgindo no período anterior. Treinados para liderança em suas igrejas, esses jovens começaram a ter logo prerrogativa nos quadros estudantis que formavam os centros acadêmicos nas escolas superiores e, assim, passaram a ver a realidade sob outro ângulo, ou melhor, voltariam suas faces para o mundo real. Perceberam o quanto suas igrejas estavam alheias ao que se passava fora de suas portas. Passaram a falar outra língua e se abriu um vazio entre eles e as lideranças eclesiásticas." (MENDONÇA, 2005, p. 59-60).

15 Para discussões mais profundas sobre o projeto Godllywood, ver: TEIXEIRA, Jacqueline Moraes. Mídia e performances de gênero na Igreja Universal. Religião e Sociedade, Rio de Janeiro, 34(2): 232-256, 2014.

16 Vídeos a respeito do Congresso Mulheres Diante do Trono podem ser encontrados na plataforma YouTube, no canal do Diante do Trono, disponíveis em: https://www.youtube.com/user/DTOFICIAL/ search?query=congresso + mulheres. Acesso em: 26 maio 2019.

17 Valadão possui, em seu espaço oficial no YouTube, 423,176 inscritos. Disponível em: https://www.youtube. com/user/DTOFICIAL . Acesso em: 28 abr. 2019 
Para evangélicos com concepções tradicionais de mundo, o feminismo vislumbra acabar com a família pois, segundo eles, a mulher deixa de se dedicar ao lar para se dedicar ao trabalho e realizar desejos pessoais (CUNHA; LOPES; LUI, , 2017).

Para além das críticas e discordâncias das Feministas Evangélicas em relação à dominação masculina sobre a feminina, mediante a construção dos tradicionais papéis de gênero, elas expressam também indignação no que tange à obrigatoriedade de se submeterem à padronização de aparências e comportamentos nos ambientes eclesiais. Diante disso, é possível entender que o cristianismo influencia as ações humanas por conta de seu carácter normativo e não preserva a identidade pessoal dos indivíduos (MENDONÇA, 2007). A religião impõe uma padronização de aparências, pensamentos e atitudes aos fiéis. Tais práticas contribuem para a construção e o fomento de uma constante vigilância de uns sobre os outros. Desse modo, as mulheres que não seguem o padrão hierárquico e -coletivamente - imposto são segregadas e tratadas com desconfiança. Ester compartilhou comigo como a experiência preconceituosa foi vivida por ela:

"Em 2013 eu passei pela transição capilar porque meu cabelo era alisado e eu cortei meu cabelo quase todo pra tirar a química. Eu fiquei com apenas dois dedos de cabelo, eu parecia um menino. E aquilo chocou muito a igreja, sabe? As pessoas não entendiam a questão, o porquê de eu querer ter meu cabelo natural. Tudo lá parecia ser um bicho de 7 cabeças, isso me irrita tanto! Me cansa tanto! E eu não senti mais vontade de ficar lá naquela igreja." (Ester)

Na lógica evangélica, ser cristã é desempenhar um conjunto de práticas que performatizam para o grupo as intenções do indivíduo a respeito de Deus. Por isso, assim como na sociedade, a classe dominante dita as regras dentro de seu campo para a manutenção da coesão do tecido social (BOURDIEU, 1998), nas congregações, os líderes produzem e reproduzem discursos, objetivando orientar a vida dos fiéis. Afinal, como afirma Bourdieu (1998), a definição de um mundo conforme os interesses da classe dominante presume a reprodução de suas posições ideológicas para seus dominados, por meio da domesticação dos mesmos, ou seja, é necessário que o habitus seja introjetado sem que os dominados percebam. Nesse sentido, é importante destacar que os que dominam a alta hierarquia eclesial lutam pelo poder de produção simbólica e, por meio do seu trabalho de pedagogia, regulam, monitoram e moralizam os corpos do gênero feminino, corroborando para um construtivismo moral, que promove e reproduz a dissimetria e a hierarquia de gênero entre os fiéis.

É importante ressaltar que as Feministas Evangélicas, após contato com estudos de gênero e com a teologia feminista, deixaram de concordar com posicionamentos estabelecidos por líderes religiosos como sendo a vontade de Deus, pois perceberam neles a dominação sobre a mulher. Entretanto, a discordância em relação ao que é pregado nas igrejas não se deu de modo pacífico. A priori, elas começaram a acreditar que, por terem se tornado feministas, não poderiam mais crer em Deus. A respeito dos conflitos internos que experienciaram, as Feministas Evangélicas relatam que:

"Num primeiro momento eu fiquei em choque, porque quando eu me deparei com o feminismo eu pensei: 'meu Deus será que o que eu tô fazendo agora é errado?' Porque lá na igreja eles dizem que o papel da mulher é ser submissa ao homem e bla bla bla... essas coisas errôneas que são pregadas por muitos padres e pastores. Então primeiro eu tive esse impacto e depois eu entendi que o feminismo tem de estar em todas as instâncias da sociedade. É principalmente na igreja que o feminismo tem que estar, porque eles disseminam muitas coisas erradas." (Noemi) 
"Eu entrei em crise quando eu comecei a entender que as passagens bíblicas eram usadas como um 'cala boca', né. Eu entrei em crise, crise mesmo. De passar noites chorando, sabe. Porque eu não entendia como Deus permitia que a gente sofresse tanto. Eu me questionei muito. Daí depois eu percebi que eu tinha que fazer uma separação do que era a igreja e do que era a fé. A instituição é uma coisa e a fé é outra coisa, aí eu consegui lidar melhor com essa questão de ser feminista e evangélica." (Ana)

"Para mim, me perceber feminista, foi conflitante porque no início eu achava que se eu fosse feminista eu não ia mais poder ter minha fé e que eu ia ter que falar mal de Deus. Mas aí quando eu vi que o feminismo tem a ver com escolha, é você quem decide, eu fiquei assim: 'oh, mas é isso?' Sabe, é por isso que eu digo que eu me senti uma pessoa muito mais leve depois que eu conheci o feminismo.” (Ester)

Nota-se que o movimento de construção de uma nova identidade, alicerçada de forma consciente e racional, quando em contraste com a experiência religiosa introjetada de modo patriarcal - através das instituições socializadoras como igreja e família, por exemplo - pode provocar, a princípio, sentimento de culpa nas mulheres. Para Boff (2002), a manifestação do sentimento de culpa e dor pode ocorrer, pois mudar a perspectiva a respeito do que é conhecido significa romper com formas de pensar e visões de mundo que traziam segurança ao indivíduo, inclusive a respeito de sua própria identidade. Hall (2006), diante da mesma perspectiva de Boff, defende que pode ocorrer conflito interno quando o indivíduo é deslocado de seu lugar no mundo. Segundo o autor, o sujeito é consequentemente deslocado de si mesmo quando crenças que eram consideradas imutáveis se transformam em experiência de dúvida. "A assim chamada 'crise de identidade' é vista como parte de um processo mais amplo de mudança, que está deslocando as estruturas e processos culturais das sociedades modernas e abalando os quadros de referência que davam aos indivíduos uma ancoragem estável no mundo social." (HALL, 2006, p. 7).

Entretanto, as Feministas Evangélicas não tiveram que enfrentar divergências somente em ambientes eclesiais ou superar apenas problemas de ordem individual ou interna. Elas me relataram também que, durante a transição da antiga identidade para a nova, tiveram que transpor discordâncias familiares por conta da não compreensão, por parte de seus consanguíneos, em relação às suas recém-adquiridas concepções e práticas religiosas. A respeito dos conflitos experienciados na esfera privada, trago, como ilustração, as falas de Noemi e Débora, que narraram o seguinte:

“Eu sempre ouvi 'você não pode ser feminista e cristã'. Eu já sofri preconceito até mesmo na minha própria família. Quando eu comecei a me posicionar sobre o feminismo, as pessoas mais conservadoras me acharam uma herege sabe. Porque eu venho de uma família evangélica muito tradicional, por parte de mãe, e mudei muito. Até o marido de uma prima mudou totalmente comigo. Ele é aquele cara que tá fazendo de tudo pra se tornar pastor, sabe." (Noemi)

"Já houve discussões em que meu pai falou alto comigo, em que ele ficou vermelho de raiva porque ele não tava entendendo o porquê de eu tá tomando aquele posicionamento. Minha mãe também me confrontou poque eu não ia a igreja. Pra ela, é uma pergunta muito natural porque 'se você é cristão você tem ir na igreja' e eu tive que explicar pra ela que eu não acreditava nesse formato de vivência da fé. E aí eu citei pra ela inclusive um exemplo de Jesus. Ele vivia a fé dele caminhando pelas ruas e conversando 
com as pessoas, não tinha nada a ver com se reunir em templos. Na minha cabeça, eu entendo esses questionamentos como filosóficos. São sobre como você interpreta a vida, o mundo, a coletividade, a sociedade, o seu papel no mundo... enfim. Mas os questionamentos sempre terminam em silêncio ou eles viram as costas e saem porque eles não sabem responder, não sabem argumentar as questões que eu levanto quando eles vêm me confrontar. Mas na verdade, eles resistem sem saber, sem entender o porquê que eles tão resistindo." (Débora)

Identificamos que o segmento mais velho desses núcleos familiares religiosos tradicionais não apreende que muitos dos comportamentos tidos como cristãos são instituídos por meio de construção social e se mostra resistente em aceitar ou respeitar as escolhas das gerações mais novas. Percebi que a necessidade que indivíduos mais antigos têm de praticarem a fé de modo institucional advém da crença introjetada por autoridades eclesiásticas que proíbem a salvação por meio de uma busca individual (BOURDIEU, 2007). Dito de outro modo, o discurso dominante tende a impor a ordem - por ele estabelecida como natural - por meio de estruturas mentais propositalmente ajustadas à manutenção das estruturas sociais.

É importante destacar que toda estrutura só possui eficácia porque há a confiança na legitimidade da palavra dos líderes religiosos (BOURDIEU, 2007). Como a visão de mundo das Feministas Evangélicas mudou, o discurso cristão hegemônico deixou de fazer sentido e perdeu eficácia sobre elas. Em outras palavras, as Feministas Evangélicas passaram a conceber a prática da religião a partir de uma construção racional e não mais mítica, ou seja, para elas, - não se faz necessário o intermédio do líder religioso para que possa ocorrer o contato com o divino.

Portanto, é compreensível que as Feministas Evangélicas - a partir de novas concepções racionalmente adquiridas - transformem o exercício de suas práticas religiosas, adaptando-as de modo a tomarem para si apenas o que lhes faz sentido dentro do contexto de suas próprias vivências. A respeito do exercício de suas práticas religiosas mantidas, elas me expuseram que fazem suas leituras bíblicas, escutam músicas gospel e só realizam sacrifícios - como a prática do jejum, por exemplo - a partir de um acordo direto com Deus e não mais por obrigação eclesial. Elas também defendem que a experiência de um relacionamento mais íntimo com Deus, sem a obrigatoriedade de uma vivência institucionalizada, traz mais alegria e paz interior. E classificam as igrejas como "ambientes tóxicos, nos quais as mulheres não são respeitadas e a competição feminina é incentivada".

Diante da opção de escolha, algumas das entrevistadas vivenciam a fé de maneira autônoma. Por isso, identifiquei que esse segmento de Feministas Evangélicas pode ser incluído na categoria "desigrejadas" (FERNANDES; PITTA, 2006). Essa classificação foi criada por sociólogos da religião para indicar indivíduos que possuem religiosidade ${ }^{18}$, creem que são capazes de terem acesso direto ao sagrado, mas não se veem pertencendo a nenhuma igreja.

É importante destacar que, para além de transformações no âmbito do pensamento religioso e do enfrentamento de conflitos pessoais e coletivos, como já abordei, o conhecimento do feminismo também propiciou às Feministas Evangélicas a construção de uma nova identidade, mais segura de si e consciente dos direitos e deveres sociais. A respeito do processo de desconstrução e de reconstrução de suas identidades, elas declaram:

18 No caso das Feministas Evangélicas que deixaram de frequentar suas igrejas, lemos a religiosidade como Fé em Deus vivida de modo pessoal, particular, individual. Ou seja, abdicaram da vivência religiosa institucional, mas mantiveram práticas religiosas adquiridas na igreja que continuaram lhes sendo pertinentes no âmbito privado. 
"Quando você conhece e começa a estudar o feminismo, tu toma tanto posse daquilo ali, ou ele que te toma, e aí tu te torna uma pessoa tão empoderada. Não tem aquele negócio que diz que o que vem de baixo não te atinge? Então, o que vem de outra pessoa não te atinge. O que vem da outra pessoa não te faz diferença nenhuma, se ela vai te aceitar ou não. Tô nem aí sabe.” (Débora)

“Tudo mudou na minha vida após o feminismo, toda a minha forma de pensar. Mudou, tudo cara! Eu sempre tive problemas de autoaceitação, mas depois que eu entendi eu me senti uma pessoa mais livre." (Rebeca)

"Quando eu me tornei feminista, um namorado que tinha na época não gostou. Então muita coisa eu fui explicando pra ele, porque ele tinha que passar pelo processo de entendimento sobre o que é o feminismo pelo qual eu passei. E em muita coisa ele mudou, passou a concordar comigo. Mas em outras coisas não. Por exemplo, ele sempre falava que se a gente casasse eu tinha que involuntariamente colocar o sobrenome dele e que nossos filhos teriam apenas o sobrenome dele. Eu nunca concordei com isso. (Noemi)

No plano pessoal, é interessante perceber que o feminismo não só foi um fator construtor de uma identidade feminina mais segura de si, mas também operou como uma fonte de autoconhecimento, que revelou às mulheres a importância de seus nomes enquanto categoria de pertencimento próprio.

No tocante à esfera social, todas as entrevistadas declaram que é extremamente necessário debater o feminismo nas igrejas, pois as mulheres precisam ser alertadas em relação ao domínio masculino e à violência de gênero, para saberem como proceder caso isso ocorra. E é exatamente a respeito do combate das agressões em ambientes eclesiais e domésticos que tratarei a seguir.

\section{O combate da violência de gênero pelas evangélicas}

Nos relatos encontrados em campo, tanto por meio da netnografia, quanto através das narrativas das entrevistadas e da teoria pesquisada, identifiquei que a violência de gênero é o maior - e mais recorrente - problema enfrentado pelas mulheres evangélicas. Em entrevista que nos foi concedida, a pesquisadora Valéria Vilhena contou que fez trabalho de campo para a elaboração de dissertação sobre violência doméstica, na Casa Sophia ${ }^{19}$, situada no Jardim Ângela ${ }^{20}$, e que, ao conversar com as coordenadoras responsáveis pela manutenção do projeto de acolhimento das vítimas, teve conhecimento de que na casa havia a presença de mulheres evangélicas. Segundo ela, a Casa Sophia realizava 1200 atendimentos gratuitos por mês e, dentro desse contingente, $40 \%$ das mulheres atendidas se declaravam evangélicas (VILHENA, 2009).

É importante informar que a falta de abordagem e o apartamento dos evangélicos em relação aos debates que tenham por tema a violência doméstica é uma prática antiga e agravante do problema. Na década de 1990, a sociedade civil do Rio de Janeiro criou a Campanha pela Redução da Violência contra a Mulher. Sabendo que as igrejas possuem acesso às mulheres periféricas que não são amplamente abarcadas pelo Estado, convidaram os evangélicos para atuarem, unidos à sociedade civil, nesses espaços de maior segregação social e de ausência de manifestação do poder público. Entretanto, o engajamento foi ínfimo. Ao passo que os assistentes sociais acreditavam que as mulheres deviam se afastar do agressor, os religiosos

\footnotetext{
19 Casa de acolhimento para mulheres vítimas de violência doméstica, mantida pela Igreja Católica.

20 Um populoso e violento bairro da Zona Sul de São Paulo.
} 
defendiam que o casal deveria permanecer unido para que a família não fosse destituída (MAFRA, 2001). Diante da ótica evangélica tradicional, o problema da violência doméstica deve ser resolvido mediante a prática da oração e de comportamento subalterno ou passivo por parte das mulheres, para que a ira do marido não seja manifestada (VILHENA, 2009).

O que se espera das mulheres evangélicas é obediência e submissão. Por isso, muitas delas são orientadas por suas lideranças religiosas a resolverem seus problemas somente por meio da oração. Como me relatou Noemi:

"Principalmente de periferia, a mulher é evangélica, mas o homem não é. Então é o discurso do tipo: 'Olha a gente tem que orar, você tem que ser sábia pra ele sair dessa vida, você tem que trazer o seu marido pra cristo.' Mas o discurso nunca é do tipo: 'olha se ele tiver te agredindo, é melhor você rever aí porque não dá pra continuar com um marido assim'. Então, mesmo as pastoras, reproduzem o discurso machista sim. (Noemi)

Diante da mesma lógica do medo de envergonhar a família e a sua comunidade religiosa, mulheres evangélicas em situações de violência tendem a não denunciar seus companheiros. Essa afirmação emergiu diante de relatos de campo e de entrevistas, nos quais mulheres apontaram que outras próximas a elas, mesmo em situação de violência, ao pedirem ajuda a seus líderes religiosos, foram orientadas a não denunciarem o agressor e resolverem o problema por meio da oração. Diante da crença tradicional evangélica, a oração é vista como o modo mais eficaz de resolver os problemas que acometem a vida de uma mulher. Vilhena (2009) também aponta que, nesse âmbito religioso, todo problema é entendido como sendo de ordem espiritual. Portanto, a manifestação da violência nesse meio é vista como "investidas" do demônio, que ocorrem, segundo os fiéis, mediante o enfraquecimento espiritual da mulher.

Diante da perspectiva evangélica tradicional, dar voz à vítima e levá-la à delegacia, além de promover um desajuste no sistema de valores, também afeta o ordenamento social da comunidade religiosa, visto que a mulher é tida, nesses espaços, como um ser inferior ao homem e que, a partir do momento da denúncia, ela passa a exercer um lugar de poder sobre aquele que a dominava. Também é importante ressaltar que, por conta da crença na eficácia do poder da oração, dentro da comunidade evangélica, a mulher que denuncia o companheiro é estigmatizada por ser considerada como fraca, descrente da fé em Deus e em sua provisão divina. Por isso, com o objetivo de desconstruir esse pensamento do senso comum religioso, o Projeto Redomas criou um material ${ }^{21}$ pedagógico intitulado: "Não éfalta de oraşão - cartilha de combate à violência contra mulher em igrejas e comunidades cristãs" (PROJETO REDOMAS, 2018) para conscientizar as mulheres a respeito da violência de gênero e incentivá-las a denunciarem seus agressores.

21 Cartilha Projeto Redomas. Disponível em: http://projetoredomas.com/wp-content/uploads/2018/07/ cartilha-redomas.pdf. Acesso em: 12 dez., 2018. Também no site do Projeto Redomas, é possível encontrar textos, podcast, estudos bíblicos indutivos, transcrições de áudio de relatos pessoais e materiais a respeito da violência contra a mulher. 
As Feministas Evangélicas defendem que, para combater a violência de gênero, é necessário quebrar o silêncio. Para elas a forma mais potente e eficaz de poder é a palavra, porque "o falar não se restringe ao ato de emitir palavras, mas de poder existir" (RIBEIRO, 2017, p. 64). Dada a facilidade da criação e repercussão de conteúdo, Castells (2013) afirma que a internet dá voz aos indignados. Por isso, percebi a internet como um lugar de maior liberdade de expressão, no qual a voz feminina não seria silenciada e/ou constrangida como costuma ocorrer nas igrejas. Por isso, afirmo que é exatamente no ambiente virtual que as Feministas Evangélicas encontram espaço para externalizarem seus pensamentos e ações. É na, e por meio da, internet que as integrantes do grupo Feministas Cristãs, do coletivo Evangélicas pela Igualdade de Gênero $^{22}$ e do coletivo Projeto Redomas ${ }^{23}$ alertam as fiéis sobre as mais variadas formas de violência e orientam-nas a respeito de como devem proceder para se protegerem caso algum fato agressivo ocorra.

É importante destacar que o meio virtual proporciona não só a liberdade, como também a visibilidade. Desse modo, é possível alertar mulheres sobre as mais variadas questões que perpassam o cotidiano e fazer denúncias sobre ocorrência de casos de violências e abusos, como, por exemplo: o assédio cometido em meio eclesial, praticado por lideranças e/ ou membros do gênero masculino. Entretanto, constatei que a atuação das Feministas Evangélicas na rede possui eficácia em relação a seu público-alvo - seguidoras das páginas da rede social Facebook - mas não é capaz de dissolver preconceitos de indivíduos com concepções tradicionais de mundo.

Destaco ainda que, para além de todo o trabalho de caráter informativo feito na internet pelas Feministas Evangélicas, faz-se necessário haver debates orientados para o combate da violência de gênero nos ambientes religiosos. Entretanto, até a presente data de elaboração deste artigo, o único grupo de Feministas Evangélicas que atua dentro e fora da esfera virtual é o coletivo Evangélicas pela Igualdade de Gênero. E elas afirmam que, para que o diálogo com a comunidade de fiéis atinja algum nível satisfatório de troca de informação e de atenção, é necessário utilizar palavras que não sejam ligadas ao feminismo nem ao pensamento político de esquerda a fim de que se evite acionamento de pânicos morais ou preconceitos dos fiéis. O objetivo é que os fiéis não façam julgamentos de valor e de moral que lhes despertes sentimento de desconfiança.

Para os evangélicos tradicionais, o feminismo e tudo que é relacionado a ele tem por objetivo por fim na família (CUNHA; LOPES; LUI, 2017). Portanto, quando as mulheres da $\mathrm{EIG}^{24}$ organizam alguma reunião nas igrejas, para debaterem a respeito da violência de gênero, elas nomeiam esses encontros das seguintes formas: "Reunião de mulheres", "Encontro de mulheres", "Fórum feminino" e "Oração das mulheres". Valéria, fundadora da EIG, também ressalta a importância da escolha da linguagem para que a mensagem transmitida às fiéis seja compreendida. Nas palavras dela:

22 O grupo Evangélicas pela Igualdade de Gênero foi criado por Valeria Vilhena, durante o Fórum Pentecostal Latino-americano e Caribenho (FPLC), no ano de 2015 e surgiu na rede social Facebook, através da página Evangélicas pela Igualdade de Gênero, também no mesmo ano. Atualmente a página conta com 5.211 seguidores. Disponível em: https://www.facebook.com/mulhereseig/.

Acesso em: 15/11/2019.

23 A página do Projeto Redomas, na rede social Facebook, atualmente possui 5.526 seguidores.. Disponível em: https://www.facebook.com/projetoredomas/ Acesso em: 15 nov. 2019.

24 Evangélicas pela Igualdade de Gênero. 
"Nós somos mulheres, protestantes, evangélicas, feministas e antissistêmicas. E nós não trabalhamos qualquer feminismo. Nós optamos por um feminismo popular. Nós não trabalhamos a partir de um feminismo acadêmico, nós trabalhamos a partir de um feminismo popular porque a maioria das nossas igrejas são compostas de mulheres e a maioria das nossas mulheres são mulheres pobres, negras e trabalhadoras." (Valéria)

Para além da EIG, é importante mencionar que há projetos orientados para o combate da violência de gênero no campo evangélico, como o Projeto RAAB ${ }^{25}$, da IURD ${ }^{26}$, por exemplo. Entretanto, a partir dos relatos de algumas entrevistadas e do trabalho acadêmico realizado por Mendes et al. (2017), constatei que o mesmo não possui muita repercussão e eficácia.

\section{Considerações Finais}

De modo categórico, as Feministas Evangélicas afirmam que as mulheres são vítimas de uma estrutura patriarcal que as oprime e as domina por meio da introjeção de culpa em suas mentalidades. Então, o trabalho delas vislumbra desconstruir a lógica de culpabilização das vítimas ao pregarem um evangelho acolhedor e não punitivo, que, segundo elas, tem o amor e a compreensão como referência.

Identifiquei que a racionalidade dessas mulheres é orientada a partir dos estudos de gênero e da teologia feminista. Desse modo, elas se instrumentalizam e desenvolvem repertório teórico e prático para romperem o silêncio - patriarcalmente instituído - denunciarem opressões e alertarem outras mulheres.

Afirmo, portanto, que a educação e a inserção das mulheres nas universidades, bem como suas produções acadêmicas, também são fatorem que promovem novas formas de ver o mundo e que tensionam a organização social religiosa tradicional. Entretanto, é importante ressaltar que tais informações no que tange à liberdade feminina ainda atuam de modo circunscrito, pois atingem somente o segmento de mulheres jovens e de zonas urbanas ${ }^{27}$.

Pelo fato de a religião ser uma autoridade socializadora, para que as mulheres sejam preservadas nos ambientes religiosos e domésticos, é necessário que as lideranças eclesiais façam leituras bíblicas contextualizadas e historicizadas, objetivando dignificar a vida humana, e parem de acobertar casos de violência de gênero. Dito de outro modo, a mudança do discurso pregado nos púlpitos é um fator determinante para o combate à violência de gênero. Alego que, principalmente, a partir da mudança de discurso e da implementação de práticas punitivas, é possível promover a desconstrução da agressividade e do domínio masculino, assim como incentivar a construção de novas identidades orientadas para o respeito e a valorização feminina.

25 O Projeto RAAB possui, apenas, 10 vídeos em seu canal. Todos os vídeos foram postados há mais 2 de anos. O canal conta com 617 pessoas inscritas. Disponível em: https://www.youtube.com/channel/ UCWkor7g9jisOhMO1sozXc0A/videos. Acesso em: 28 maio 2019.

26 Igreja Universal do Reino de Deus.

27 Noemi - uma das integrantes da EIG - desabafa que o maior sonho delas é conseguir capital - visto que elas realizam trabalho voluntário - para abrir um espaço de acolhimento para as mulheres periféricas e indígenas em situação de violência e de vulnerabilidade social. 


\section{Referências}

BECKER, Howard S. Outsiders: estudos de sociologia do desvio. Rio de Janeiro: Jorge Zahar, 2008.

BOFF, Leonardo. Experimentar Deus hoje: a transparência de todas as coisas.. In. MORAES, J. Ferrater. Experiência Campinas: Verus, 2002.

BOURDIEU, Pierre. "Sobre o poder simbólico" e "A identidade e a representação". In: BOURDIEU, Pierre. O poder simbólico. Rio de Janeiro: BertrandBrasil, 1998.

BOURDIEU, Pierre. Economia das trocas simbólicas. São Paulo: Perspectiva, 2007.

BUTLER. Judith. Relatar a si mesmo: crítica da violência ética. Belo Horizonte. Autêntica. 2015.

CASTELLS, Manuel. O poder da identidade. São Paulo: Paz\&Terra, 2008.

CASTELLS, Manuel. Redes de indignação e esperança: movimentos sociais na era da internet. 1 . Ed. Rio de Janeiro: Zahar, 2013.

CUNHA, Christina V.; LOPES, Paulo Victor Leite; LUI, Janayna. Religião e Politica: medos sociais, extremismo religioso e as eleições 2014. Rio de Janeiro: Fundação Heinrich Böll e Instituto de Estudos da Religião (ISER), 2017.

DA MATTA, Roberto. O oficio de etnólogo, on como ter anthropological blues. Boletim do Museu Nacional: Antropologia, n. 27, maio de 1978.

DUARTE, Rosália. Pesquisa Qualitativa: Reflexões sobre o trabalho de campo. Cadernos de Pesquisa. n.115, p.139-154, março, 2002.

FERNANDES, Sílvia R. A.; PITTA, Marcelo. Mapeando as rotas do trânsito religioso no Brasil. Religião e Sociedade. Rio de Janeiro, v. 26, n.2, p.120-154, 2006.

GUEDES, Moema. Família e trabalho nas mulheres de nível universitário: um olhar demográfico. Gênero, Niterói, v. 9, n. 1. 2009.

HALL, Stuart. A identidade cultural na Pós-Modernidade., 11. ed. Rio de Janeiro: DP\&A Editora, 2006.

LEMOS, A.; LÉVY, P. O Futuro da Internet: em direção a uma ciberdemocracia planetária. São Paulo: Paulus, 2010.

MARCUS, George. Etnografía en/del sistema mundo. El surgimiento de la etnografía multilocal. Alteridades, v. 11, n.22, p. 111-127, 2001.

MAFRA, Clara. Os evangélicos. Rio de Janeiro: Jorge Zahar, 2001.

MENDES, Daine; NASCIMENTOS, Beatriz. Reféns da fé: mulheres evangélicas sofrem mais violência? São Paulo: Editora Casa Flutuante, 2017.

MENDONÇA, Antonio Gouvêa. O protestantismo no Brasil e suas encruzilhadas. Revista USP, São Paulo, n.67, p. 48-67, set./ nov., 2005.

MENDONÇA, Antonio Gouvêa. Protestantismo no Brasil: um caso de religião e cultura. Revista USP, São Paulo, n.74, p. 160-173, junho/agosto 2007.

PROJETO REDOMAS. Não é falta de oração: cartilha de combate á violência contra mulher em igrejas e comunidades cristãs. São Paulo: Redomas, 2018.

RIBEIRO, Djamila. O que é lugar de fala?. Belo Horizonte: Letramento: Justificando, 2017. 
ROSAS, Nina. O direito ao corpo: liberdades e controles a partir dos ensinamentos da pastora Ana Paula Valadão. ANPOCS, 2016.

ROSADO-NUNES, Maria José. Feminismo, gênero e religião: os desafios de um encontro possível. Estudos da Religião, v. 31, n.2. 65-76, maio-ago, 2017.

TEIXEIRA, M. Jacqueline. Mídia e performances de gênero na igreja Universal: o desafio Godllywood. Religião e Sociedade, Rio de Janeiro, v, 34, n. 2, p. 232-256, 2014.

VILHENA, C. Valéria. Pela voz das mulheres: uma análise da violência doméstica entre mulheres evangélicas atendidas no Núcleo de Defesa e Convivência da Mulher - Casa Sofia. 2009. Dissertação (Mestrado em Ciências da Religião) - Universidade Metodista de São Paulo, São Paulo, 2009. 